\title{
Cell Production and Cell Death in the Generation of Variation in Neuron Number
}

\author{
Richelle C. Strom and Robert W. Williams \\ Center for Neuroscience, Department of Anatomy and Neurobiology, University of Tennessee, \\ Memphis, Tennessee 38163
}

\begin{abstract}
Retinal ganglion cell numbers in adult mice vary from 40,000 to 80,000 . Much of this variation and the prominent bimodality of strain averages are generated by allelic variants at the neuron number control 1 (Nnc1) locus on chromosome 11. The Nnc1 locus may modulate either ganglion cell production or the severity of ganglion cell death. Here we have determined what the relative contributions of these two processes are to variation in adult cell number by estimating total ganglion cell production in 10 strains of mice (A/J, BALB/CJ, BXD32, C57BL/6J, CAST/Ei, CARL/ChGo, CE/J, C3H/HeSnJ, DBA/2J, and LP/J). These strains have adult populations that range from 45,000 to 76,000 (data available at http://qtl.ml.org). We estimated cell production by counting ganglion cell axons after ganglion cell neurogenesis but before the onset of significant cell death. Total
\end{abstract}

Numbers of retinal ganglion cells range from 50,000 in nocturnal rodents to several million in diurnal birds and primates (Rager and Rager, 1978; Rakic and Riley, 1983; Finlay and Pallas, 1989; Williams et al., 1996). Variation is also marked within species; numbers range from 0.7 to 1.5 million in humans (Curcio and Allen, 1990) and from 40,000 to 80,000 in mice (Williams et al., 1996). In mice, the distribution of strain averages is bimodal, with distinct modes centered at 55,000 and 64,000. We have demonstrated that this variation is primarily genetic, with a heritability of $\sim 0.8$ (Williams et al., 1996). We subsequently discovered that most of the bimodality in strain averages is controlled by a major quantitative trait locus, neuron number control 1 (Nncl). This quantitative trait locus is located on chromosome (Chr) 11 and is closely linked to three genes known to influence retinal development-the retinoic acid receptor $\alpha$, neuregulin, and the thyroid hormone receptor $\alpha$ (Williams et al., 1998a). Nnc1 may influence ganglion cell number by modulating either cell production or the severity of natural cell death.

Our principal objectives in this study were to determine the developmental mechanism by which allelic variants at $\mathrm{Nncl}$ control neuron number and to assess the relative contributions of cell production and cell death to the consistent and pronounced differences in population size among strains of mice. We examined ganglion cell production in 10 strains-four selected from

\footnotetext{
Received June 4, 1998; revised Sept. 15, 1998; accepted Sept. 18, 1998.

This research was supported by grants from the National Institutes of Health to R.W. (National Institute of Neurological Disorders and Stroke Grant R01 NS35485 and NEI Grant EY08868). R.C.S. was supported in part by the United States Public Health Service Training Grant RNS-07323. We thank K. Troughton for technical help and D. Goldowitz for providing us with M. caroli pups.

Correspondence should be addressed to Dr. Robert W. Williams, Department of Anatomy and Neurobiology, 855 Monroe Avenue, Memphis, TN 38163.

Copyright (C) 1998 Society for Neuroscience $\quad 0270-6474 / 98 / 189948-06 \$ 05.00 / 0$
}

cell production ranges from 131,000 to 224,000 , and most of the variation in adult ganglion cell number is explained by this significant variation in cell production. In contrast, the percentage of cell death is relatively uniform in most strains ( $\sim 69 \%$ cell loss). The exceptions are BXD32, a strain that has an extremely high adult cell population, and Mus caroli (CARL/ChGo), a wild southeast Asian species that is distantly related to laboratory strains. In BXD32 and M. caroli, $\sim 62 \%$ of the population dies. Our analysis indicates that substitutions of single alleles at the Nnc1 locus are responsible for production differences of $\sim 8000$ ganglion cells.

Key words: neurogenesis; cell death; genetic variation; Nnc1; retinal ganglion cell; strain variation; retinal development the low mode, four from the high mode, and one each from the high and low extreme (see Fig. 1). We specifically included strains C57BL/6J and DBA/2J, the parental strains of the set of recombinant inbred mice used to map Nncl. Mechanisms generating neuron number differences between these two strains can be more confidently assigned to Nncl. Total ganglion cell production was estimated by counting retinal ganglion cell axons at birth, a time at which ganglion cell generation in mice is complete (Dräger, 1985) but before significant ganglion cell death has begun (Linden and Pinto, 1985).

\section{MATERIALS AND METHODS}

Animals. As illustrated in Figure 1, strains of mice were chosen primarily to represent the two major modes in ganglion cell number (Williams et al., 1996). Three standard inbred strains were selected from the low mode $(\mathrm{C} 57 \mathrm{BL} / 6 \mathrm{~J}, \mathrm{~A} / \mathrm{J}$, and $\mathrm{LP} / \mathrm{J})$ and four standard inbred strains were selected from the high mode (BALB/cJ, C3H/HeSnJ, CE/J, and DBA/2J). All of these strains were obtained from the Jackson Laboratory (Bar Harbor, ME). In addition, we selected two strains, CAST/Ei and BXD32, that have exceptionally low and high ganglion cell numbers, respectively. BXD32 was obtained from Dr. Benjamin Taylor at the Jackson Laboratory. CAST/Ei is an inbred strain derived from Mus musculus castaneus that we obtained from Dr. Eva Eicher at the Jackson Laboratory. Finally, we studied an outbred sample of Mus caroli that we refer to as CARL/ChGo, a strain that falls into the low ganglion cell mode. CARL/ChGo is a partially inbred strain of $M$. caroli given to us by Dr. Dan Goldowitz at the University of Tennessee. Both CARL/ChGo and CAST/Ei are representatives of wild species endemic to southeast Asia. All mice were mated in our colony to produce neonates. The day of birth was designated postnatal day $0(\mathrm{P} 0)$.

Tissue preparation. We anesthetized neonates by placing them on ice for several minutes. Neonates were then perfused transcardially with 0.1 M PBS $(0.9 \%)$, followed by fixative $(2.5 \%$ glutaraldehyde and $2.0 \%$ paraformaldehyde in $0.1 \mathrm{M}$ phosphate buffer). Midorbital segments of optic nerves were dissected, osmicated, and embedded in Spurr's resin. Nerves were thin-sectioned, placed on formvar-coated grids, and stained with lead citrate and uranyl acetate. 


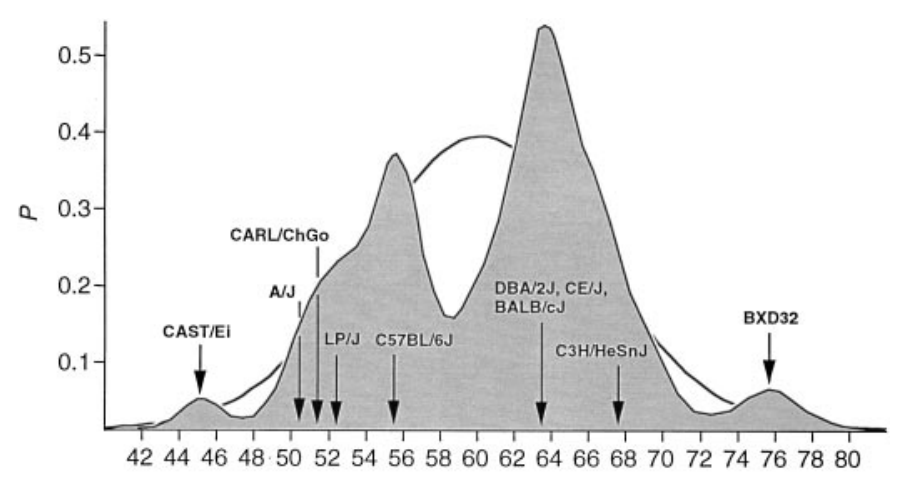

Adult Ganglion Cell Number (x1000)

Figure 1. Bimodal distribution of adult ganglion cell averages for 60 inbred strains. The strains include 38 recombinant and 17 standard inbred strains listed by Williams et al. (1996) and 5 additional strains, 3 of which are included in this study. A Gaussian probability distribution was computed for each strain and summed to obtain a probability density plot (for methods, see Williams et al., 1996). The figure shows that most strains fall into two main modes. The Gaussian function drawn in the background has a mean of $60.6 \pm 6.3(\times 1000)$, the average \pm SD of the 60 strains. The arrows designate the strain averages for the 10 strains examined in this study.

Estimating ganglion cell number. We estimated ganglion cell numbers by counting axons in optic nerve cross-sections (Williams et al., 1996). Previous studies have demonstrated that axon counts are reliable estimates of ganglion cell number; bifurcating axons, retinopetal axons, and retinoretinal axons are comparatively rare in mammals even during development [Perry et al. (1983); Chalupa et al. (1984); Lia et al. (1986); Williams et al. (1986); Rice et al. (1995), see their Table 2]. Nerves were photographed in a grid pattern at $\sim 30,000 \times$ using a JEOL EX2000II electron microscope. High and low magnifications were calibrated for each case by photographing a grid replica (2160 lines/mm; EMS, Fort Washington, PA). Unmyelinated axons were easily identified (Fig. 2). Axons were counted directly on negatives within a $63 \mathrm{~mm} \times 86 \mathrm{~mm}$ counting frame. Total axon estimates were calculated by multiplying the mean axon density by the total area of the optic nerve.

We counted necrotic axons in neonatal optic nerves from two strains belonging to the high mode and two strains belonging to the low mode. We did this by systematically scanning the entire optic nerve crosssection for necrotic axons at $15,000 \times$. The criteria for distinguishing necrotic axons are those described by Williams et al. (1986). We also searched for growth cones in the sample of photographs used for counting axons and by scanning several optic nerves at high magnification $(>40,000 \times)$.

Random numbers for Monte Carlo simulations were generated in Microsoft Excel 98. These numbers were drawn from a normal distribution with seed parameters (mean $\pm \mathrm{SD}$ ) taken from our experimental ganglion cell distributions (see Fig. 4 legend for more details).

\section{RESULTS}

The retinal ganglion cell population at birth ranged from 131,000 to 224,000 (Table 1). The mean for all 46 cases is $182,500 \pm 4400$ $( \pm \mathrm{SE})$. This value is almost three times higher than the average for an equally diverse sample of adult mice (Williams et al., 1996). On average we counted five neonates per strain. The coefficient of variation within strains averaged $8.2 \%$, only slightly higher than the $7.2 \%$ value obtained for adult mice (Williams et al., 1996). The small increase is probably caused by the technical difficulty of counting axons before they are myelinated. Given the anticipated variation in the stage of maturation of sets of neonatal mice killed at birth, this coefficient of variation is low and suggests that the ganglion cell population within a strain is comparatively stable at this stage of development. The average coefficient of error (the SE divided by the sample mean) averaged $4.5 \%$ in neonates and

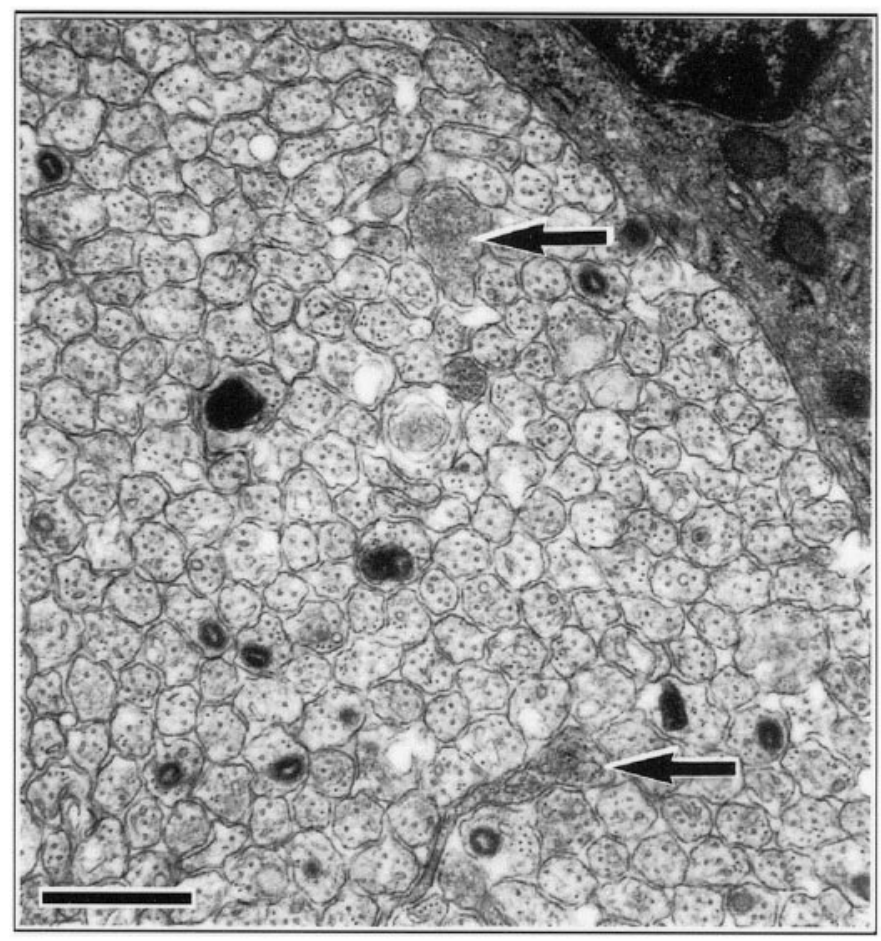

Figure 2. Electron micrograph from a cross-section of a neonatal optic nerve $(\mathrm{C} 3 \mathrm{H} / \mathrm{HeSnJ})$. Magnification is $15,000 \times$. Axons at this stage have a relatively uniform diameter, with a mean fiber diameter of $\sim 0.4 \mu \mathrm{m}$. Axons can be recognized unambiguously in well-fixed tissue. The two structures marked by arrows are astrocyte processes and were not counted. Scale bar, $1 \mu \mathrm{m}$.

$2.5 \%$ in adults. These values provide an assessment of the reliability of adult and neonatal ganglion cell counts.

\section{Cell production}

If strain differences in adult ganglion cell numbers result from differences in the number of neurons that are generated, then at birth each strain should have a population that is approximately threefold higher than its adult mean. The slope of the regression should be close to $1 / 3$, and the correlation should be high. This is what we found. The slope of a free regression for the 10 strains is $0.26 \pm 0.07$ (Fig. 3). Forcing the regression line through the origin produces the expected slope of $1 / 3$ with an excellent fit (Fig. 3, inset). The positive $y$-intercept (11,600 adult cells) in the free regression may result from sampling error or nonlinearity of cell death or may indicate a basal level of cell production. The correlation coefficient of the free regression in Figure 3 is 0.81 , and the corresponding coefficient of determination $\left(r^{2}\right)$ is 0.66 . Thus, two-thirds of the variance in adult cell number can be readily explained by strain differences in cell genesis.

We were particularly interested in understanding the process that produces the bimodality of adult strain averages, and for this reason we also restricted the analysis to the eight strains belonging to high and low modes (Fig. 3, dark line). The coefficient of determination for this subset of points is 0.77 , indicating that the bimodality is generated primarily by differences in ganglion cell production. The remaining "unexplained" variance must result from strain differences in the severity of cell death, developmental noise, and technical error.

Our statistical analysis is complicated by two factors. First, the parameters plotted in Figure 3 are not formally independent 
Table 1. Ganglion cell number and percentage of cell loss

\begin{tabular}{lllrlrl} 
Strain & Phenotype & Adult mean $\pm \mathrm{SE}$ & $n$ & P0 mean \pm SE & $n$ & $\begin{array}{l}\text { Absolute cell } \\
\text { loss } \pm \text { SE }\end{array}$ \\
\hline BXD32 & Very high & $75,800 \pm 1,900$ & 11 & $199,500 \pm 5,500$ & 6 & $123,700 \pm 5,800$ \\
C3H/HeSnJ & High & $67,800 \pm 1,400$ & 3 & $224,000 \pm 8,100$ & 5 & $156,200 \pm 8,200$ \\
CE/J & High & $63,600 \pm 2,400$ & 5 & $207,000 \pm 8,900$ & 3 & $143,400 \pm 9,200$ \\
BALB/cJ & High & $63,400 \pm 2,200$ & 8 & $180,800 \pm 7,700$ & 4 & $117,400 \pm 8,000$ \\
DBA/2J & High & $63,400 \pm 1,100$ & 13 & $202,100 \pm 7,900$ & 4 & $138,700 \pm 8,000$ \\
C57BL/6J & Low & $55,500 \pm 1,300$ & 13 & $185,700 \pm 6,400$ & 7 & $130,200 \pm 6,500$ \\
LP/J & Low & $52,200 \pm 1,900$ & 8 & $171,400 \pm 8,000$ & 5 & $119,200 \pm 8,200$ \\
CARL/ChGo & Low & $51,300 \pm 2,200$ & 11 & $131,200 \pm 5,500$ & 3 & $79,900 \pm 5,900$ \\
A/J & Low & $50,600 \pm 1,300$ & 8 & $155,600 \pm 6,000$ & 6 & $105,000 \pm 6,100$ \\
CAST/Ei & Very low & $45,000 \pm 1,000$ & 12 & $146,600 \pm 6,600$ & 3 & $101,600 \pm 6,700$ \\
\hline
\end{tabular}

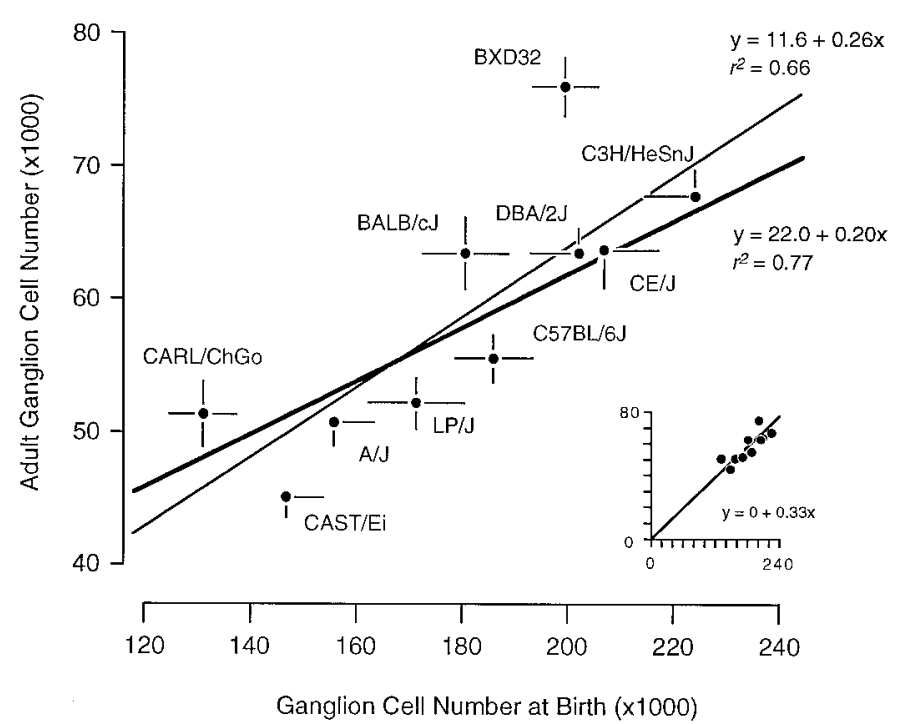

Figure 3. Regression of $\mathrm{P} 0$ and adult ganglion cell number averages for 10 strains. The error bars represent $1 \mathrm{SE}$. The thin regression line includes all strains, and the coefficient of determination for these data is 0.66 , whereas the dark regression line excludes strains CAST/Ei and BXD32, and the coefficient of determination is 0.77 . Inset, A plot of the same data but with the regression line forced through the origin.

because total cell production cannot be less than the adult population. Second, the distribution of adult values is far from normal (Fig. 1). Conventional statistical estimates are therefore difficult to interpret. To address these problems, we performed Monte Carlo simulations to test cell production and cell death models using seed parameters taken from the adult distribution. We also subtracted the adult population from the neonatal population to insure independence between the parameters (Fig. 4A). Figure 4, $B$ and $C$, shows the outcomes of two typical Monte Carlo simulations in which we plot adult cell number against the number of lost cells. The first model (Fig. 4B) assumes that all differences in adult cell number are caused by matched differences in cell production and that cell death is strictly proportional to cell production. The second model (Fig. 4C) assumes that all differences among adult strains are caused by variation in the severity of cell death and that at birth all strains have approximately the same cell population $(\sim 180,400 \pm 18,400$ cells $)$. In the cell production simulation (Fig. $4 B$ ), the regression slope is +1.2 , whereas in the cell death simulation (Fig. $4 C$ ), the slope is -1.1 .
Our actual data set (Fig. $4 A$ ) with its slope of +1.5 strongly supports a cell production model.

The 10 inbred strains were divided into high $(\mathrm{BALB} / \mathrm{cJ}, \mathrm{C} 3 \mathrm{H} /$ $\mathrm{HeSnJ}, \mathrm{CE} / \mathrm{J}, \mathrm{BXD} 32$, and DBA/2J) and low (C57BL/6J, A/J, $\mathrm{CAST} / \mathrm{Ei}, \mathrm{CARL} / \mathrm{ChGo}$, and LP/J) groups. Mean adult ganglion cell numbers for these groups are 66,800 \pm 2700 and 50,900 \pm 1900, respectively. There are highly significant differences in ganglion cell production between these groups, with means of $202,700 \pm 7800$ and $158,100 \pm 10,600$, respectively ( $t$ test, $p<$ $0.001)$. In contrast, there is no significant difference in the percentage of ganglion cell loss between high and low groups, with mean percentages of cell loss relative to neonatal values of 66.9 and $67.5 \%$, respectively ( $p=0.42)$.

Nncl was mapped using recombinant inbred strains generated from the parental strains DBA/2J and C57BL/6J. For this reason a comparison between these two strains is especially germane in discovering how Nncl modulates ganglion cell number. The severity of cell death was closely matched between DBA/2J and C57BL/6J (69 and 70\%, respectively). In contrast, DBA/2J produces $\sim 16,400$ more cells than does C57BL/6J. This result, together with our previous finding of additive gene action (Williams et al., 1998a), indicates that the substitution of a single allele at $N n c 1$ is associated with a production difference of $\sim 8000$ cells.

\section{Cell death}

With the exception of strains BXD32, CARL/ChGo, and BALB/ $\mathrm{cJ}$, the average percentage of cell death among strains is relatively uniform (Table 1, $69 \pm 1.2 \%$ ). Although the percentage of cell death is relatively uniform, the absolute magnitude of ganglion cell death is variable among strains and is highly correlated with production values (Table 1). There are some notable exceptions to this generality. The percentage of cell death in BXD32 and CARL/ChGo is significantly lower than that in other strains ( $t$ test, $p<0.05$, with Bonferroni correction). Estimates of ganglion cell production are similar in $\mathrm{BALB} / \mathrm{cJ}$ and $\mathrm{C} 57 \mathrm{BL} / 6 \mathrm{~J}$, yet these strains have adult populations that differ by $\sim 8000$ cells (Table 1 ). A slight reduction in the severity of cell death in BALB/cJ $(65 \%$ loss) seems to account for the relatively high cell number of this strain at maturity. In this instance, the marked strain difference in adult population size results primarily from variation in the severity of cell death. Differences in cell death can also compensate for differences in cell production. For example, CARL/ChGo produces an average of 131,000 ganglion cells, 20,000-40,000 fewer cells than $\mathrm{A} / \mathrm{J}$ and $\mathrm{LP} / \mathrm{J}$ produce, respectively, yet all three strains have closely matched adult populations (Table 1). 

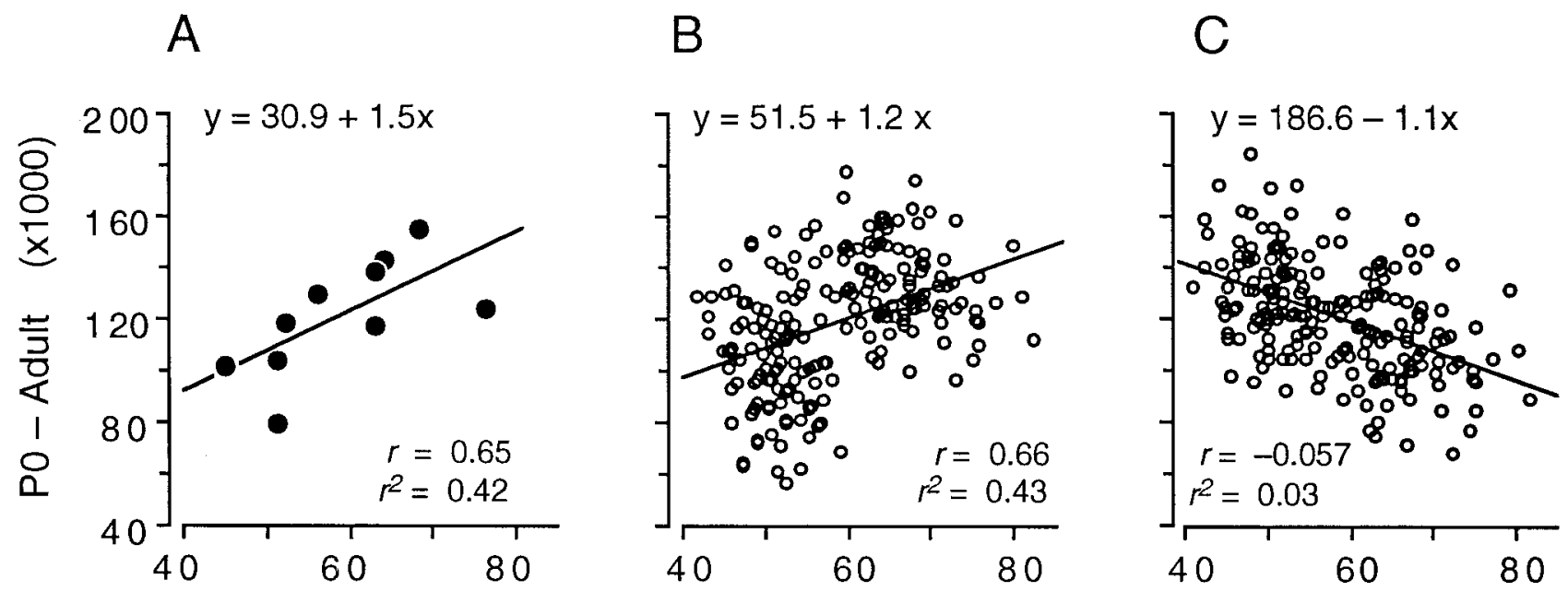

Adult Ganglion Cell Number (x1000)

Figure 4. Regression of the number of cells that are lost (number at $\mathrm{P} 0$ minus the number at maturity) and adult ganglion cell number from our data $(A)$ and two alternative Monte Carlo simulations $(B, C)$. The first model $(B)$ assumes that all differences in ganglion cell number are caused by cell production differences, whereas the second model $(C)$ assumes that all differences are caused by variation in the severity of cell death. Monte Carlo data sets consisted of 200 numbers randomly selected from normal distributions. In both models, high and low adult ganglion cell groups $(n=100$ each) were selected from two normal distributions with seed parameters (mean \pm SD) from the five high $(66,800 \pm 5400)$ and five low $(50,920 \pm 3800)$ strains that we studied. In the production model $(B)$, means were obtained from two normal distributions with seed parameters (mean \pm SD) from the five high $(202,680 \pm 15,500)$ and five low $(158,100 \pm 21,200)$ strains. In the case of the cell death model $(C)$, in which no production differences are assumed, the neonatal means were obtained from a single distribution, with a mean \pm SD of all 10 strains combined $(180,390 \pm 18,400)$. The slope obtained with our real data is $+1.5(A)$, whereas the slopes of the cell production $(B)$ and cell death $(C)$ models are +1.2 and -1.1 , respectively. The positive slope from our data is close to that of the simulated cell production model, demonstrating that differences in adult ganglion cell number are predominantly caused by differences in cell production. In these analyses, we used model I linear least-square regression, because the measurement error term is without bias. Adult ganglion cell number was subtracted from P0 ganglion cell number to make the $y$-axis formally independent of adult ganglion cell number plotted on the $x$-axis.

\section{Necrotic axons and growth cones}

The validity of our quantitative analysis depends on the assurance with which we can estimate total ganglion cell production in mice. If much cell loss occurs before birth or much cell addition occurs after birth, then production estimates based on axon counts in the optic nerve at $\mathrm{P} 0$ will be too low. To eliminate the possibility that significant cell death occurs prenatally, we counted necrotic axons in neonatal optic nerves from strains belonging to the high and low modes using criteria described by Williams et al. (1986). Necrotic axons are relatively easy to see, and it was practical to count all sites of necrosis in single optic nerve cross-sections. Necrotic axons at P0 make up 0.02 and $0.05 \%$ of the fiber population in cases selected from the low strains, A/J and C57BL/ $6 \mathrm{~J}$, respectively, whereas they make up 0.07 and $0.09 \%$ of the population in cases selected from the high strains, BXD32 and $\mathrm{C} 3 \mathrm{H} / \mathrm{HeSnJ}$, respectively. The fact that a somewhat higher incidence of necrosis was noted in nerves taken from the high strains makes it very unlikely that variation in early axon loss accounts for differences between adult values. Growth cones were exceeding rare in all material, and fewer than five profiles among all cases met even a relatively lax criteria for these structures (Williams et al., 1986; Williams et al., 1991; Colello and Guillery, 1992).

\section{Specificity of strain differences}

Do strain differences in retinal ganglion cell number correspond to differences in total brain weight, or are differences among strains specific to the ganglion cell population? The correlation of ganglion cell number and brain weight across individual mice is 0.37 , but when strain averages are used, the correlation rises to
0.75. This suggests that approximately one-half of the variance in neonatal ganglion cell number can be explained directly or indirectly by differences in brain weight. As assessed by quantitative DNA analysis, brain weight differences among neonatal mice are primarily attributable to differences in total cell number (Zamenhof and Marthens, 1976). Thus, mechanisms modulating ganglion cell number may have common effects on cell number in the other parts of the CNS. The correlation between strain averages of adult brain weight and ganglion cell number for the same strains is only 0.51 . Given the wide confidence intervals of correlations computed with low numbers of cases, the difference between the adult and neonatal correlations ( 0.51 and 0.75 , respectively) may be caused by sampling error. But it is also conceivable that strain variation in cell death decreases an initially high correlation between brain weight and retinal ganglion cell number. In any case, the cellular specificity of the strain differences is likely to be low, and we expect differences in numerous other neuronal cell populations to be closely matched with the differences we find in ganglion cell number.

\section{DISCUSSION}

\section{Synopsis}

Our analysis demonstrates that most of the variation in adult ganglion cell number among strains of mice can be traced to differences in cell production. Allelic variants at the Nnc1 locus on Chr 11 (Williams et al., 1996, 1998a) generate the pronounced bimodality in ganglion cell population size by modulating ganglion cell production. 


\section{Generation and death of retinal ganglion cells}

Generation of retinal ganglion cells in mice begins on embryonic day 11 (E11) and lasts until just before birth (Dräger, 1985). There is a short delay between neurogenesis and the time at which ganglion cell axons extend into the optic nerve (Colello and Guillery, 1992). This delay could deflate estimates of total cell production. However, very few ganglion cells are produced after E18 (Dräger, 1985), and as anticipated from the work of Colello and Guillery (1992), we did not observe growth cones in neonatal optic nerves. It is therefore unlikely that our estimates of total production are biased downward by late ganglion cell generation.

In contrast, ganglion cell death begins at, or just before, birth, peaks between postnatal days 4-6, and is essentially complete by P12 (Linden and Pinto, 1985). At the peak of cell loss, between 5,000 and 10,000 ganglion cells are eliminated per day (Williams et al., 1990). However, fewer than 2000 cells are lost on the day of birth in mice, consistent with our observation of very few necrotic axons, $<300$ per nerve. At this rate it is improbable that more than a total of 10,000 ganglion cells are lost prenatally. In chickens there is as much as a $3 \mathrm{~d}$ delay between the onset of ganglion cell degeneration in the retina and the elimination of axons in the optic nerve (Rager and Rager, 1978). If there is a similar delay in mice, then our axon counts should more directly reflect production numbers. Nonetheless, our estimates of total production may be biased downward slightly by the early loss of ganglion cell axons. However, the magnitude of this error is sufficiently small $(\sim 10,000$ cells $)$ that we did not think this loss warranted correction.

\section{Mechanism generating differences in ganglion cell production}

We recently mapped a gene, $N n c 1$, that is responsible for more than one-half of the genetic variance in ganglion cell number in mice and that generates the pronounced bimodality that we discovered among strain averages (Williams et al., 1998a). Nncl is the first locus known to control normal variation in cell number in the vertebrate CNS. The thyroid hormone receptor $\alpha$ gene (Thra) is a superb candidate gene. Thra maps within 1-2 cM of Nncl on chromosome 11 (Montgomery et al., 1997) and is expressed within the developing chick retina (Sjöberg et al., 1992). The ligand of THRA, triiodothyronine, is known to influence retinal ganglion cell fate determination (Hoskins, 1985) and retinal maturation rate (Macaione et al., 1984), and hypothyroidism during retinal development results in decreased cell density in the ganglion cell layer (Hoskins, 1985; Navagantes et al., 1996).

Nnc1, possibly Thra, could influence ganglion cell production by affecting (1) the numbers of retinal progenitor cells, (2) the pathways of cell determination, or (3) the kinetics of progenitor cell proliferation. Genetically determined differences in numbers of multipotent retinal progenitors would have consistent effects on the number of many retinal cell types. However, a comparison of horizontal cell and ganglion cell numbers for six strains demonstrates that ratios in these early-generated cell types are not always matched (Williams et al., 1998b). We have also examined other retinal cell populations and in preliminary work have found a weak negative correlation between ganglion cells and photoreceptors (Williams et al., 1998a). This suggests that there may be a reciprocal relationship between the generation of early- and late-generated retinal cell types. An example of this type of reciprocal relationship is found when the Notch signaling pathway is perturbed. This results in a shift in the ratio of early- to late-generated retinal cell types (Dorsky et al., 1997). The idea of temporally regulated competence is supported by a confluence of work (Watanabe and Raff, 1990; Anchan et al., 1991; Williams and Goldowitz, 1992; Guillemot and Joyner, 1993; Cepko et al., 1996; Alexiades and Cepko, 1997).

The progressive slowing of the cell cycle and its eventual cessation result in part from decreased availability of key exogenous factors (Jacobson, 1991; Alexiades and Cepko, 1996). Studies have identified multiple mitogenic factors for retinal progenitors: FGF, TGF $\alpha$ (Lillien and Cepko, 1992), TGF $\beta$, epidermal growth factor (Anchan et al., 1991), and IGF-1 (HernándezSánchez et al., 1995; Frade et al., 1996). Interestingly, the addition of the THRA ligand triiodothyronine to cultured fetal rat hypothalamus cells stimulates the release of IGF-1 into the culture medium (Binoux et al., 1985). Finally, genetic variants of Nncl could alter the proliferation kinetics of progenitors that give rise to ganglion cells. Rates of mitosis may be influenced via inhibitory molecules and pathways. One extremely interesting example is dopa, a tyrosine metabolite that normally has inhibitory effects on cell genesis in retina (Ilia and Jeffery, 1996). The absence of dopa in albino rats leads to an anomalous upregulation of ganglion cell production followed by an increase in the severity of cell death (Ilia and Jeffery, 1998). Nnc1 could have effects within any of these mitotic regulatory pathways.

\section{Variation in retinal ganglion cell death}

The severity of cell death is close to $68-70 \%$ in most strains of mice. However, there are three exceptional strains with less severe loss. Three to nine percent fewer cells are lost in BXD32, CARL/ChGo, and BALB/cJ. BXD32 is particularly interesting because it has the highest adult population $(75,800 \pm 1900)$ among the 60 strains we have now examined. Yet at birth BXD32 has an unexceptional number, 199,500, that is lower than that of other strains. Clearly, one or more genes controlling rates of ganglion cell death are responsible for the high adult cell number in this strain. It would be feasible to map a cell death gene by crossing BXD32 to a strain with similar ganglion cell production but higher cell death.

Variation in the severity of cell death may result from differences in titers of neurotrophic factors. The neurotrophins (BDNF and neurotrophin-3/4) have been found to increase survival of retinal ganglion cells in chicken and rat (Rosa et al., 1993; Ma et al., 1998). Neuregulin, found on the cell surface and as a secreted protein, can also increase survival of neonatal rat retinal ganglion cells in culture (Bermingham-McDonogh et al., 1996). Differences in the time of expression or concentration of these neurotrophic factors, their receptors, or components within their signaling pathways could produce variation in the severity of naturally occurring ganglion cell death.

\section{Nnc1 controls cell production}

We have shown that as much as $77 \%$ of the variation among adult strains results from differences in the production of ganglion cells. The percentage of cell death in high and low groups does not differ significantly (66.9 and $67.5 \%$, respectively). We conclude that variation in adult ganglion cell number among inbred mouse strains results predominantly from differences in cell production. Comparison of our data with the Monte Carlo simulations (Fig. 4) corroborates this conclusion.

A major motivation for undertaking the present study was to determine how and when allelic variants at Nncl influence the size of the ganglion cell population. Collectively, our results 
strongly indicate that Nncl modulates ganglion cell number by influencing cell production, and because ganglion cell production occurs before birth, our results indicate a time frame for the action of $N n c 1$.

\section{REFERENCES}

Alexiades M, Cepko C (1996) Quantitative analysis of proliferation and cell cycle length during development of the rat retina. Dev Dyn 205:293-307.

Alexiades MR, Cepko CL (1997) Subsets of retinal progenitors display temporally regulated and distinct biases in the fates of their progeny. Development 124:1119-1131.

Anchan RM, Reh TA, Angello J, Balliet A, Walker M (1991) EGF and TGF- $\alpha$ stimulate retinal neuroepithelial cell proliferation in vitro. Neuron 6:923-936.

Bermingham-McDonogh O, McCabe KL, Reh TA (1996) Effects of GGF/neuregulins on neuronal survival and neurite outgrowth correlate with erbB2/neu expression in developing rat retina. Development 122:1427-1438.

Binoux M, Faivre-Bauman A, Lassarre C, Barret A, Tixier-Vidal A (1985) Triiodothyronine stimulates the production of insulin-like growth factor (IGF) by fetal hypothalamus cells cultured in serum-free medium. Dev Brain Res 21:319-321.

Cepko CL, Austin CP, Yang X, Alexiades M, Ezzeddine D (1996) Cell fate determination in the vertebrate retina. Proc Natl Acad Sci USA 93:589-595.

Chalupa L, Williams R, Henderson Z (1984) Binocular interaction in the fetal cat regulates the size of the ganglion cell population. Neuroscience 12:1139-1146.

Colello RJ, Guillery RW (1992) Observations on the early development of the optic nerve and tract of the mouse. J Comp Neurol 317:357-378.

Curcio CA, Allen KA (1990) Topography of ganglion cells in human retina. J Comp Neurol 300:5-25.

Dorsky RI, Chang WS, Rapaport DH, Harris WA (1997) Regulation of neuronal diversity in the Xenopus retina by Delta signalling. Nature 385:67-70.

Dräger U (1985) Birth dates of retinal ganglion cells giving rise to the crossed and uncrossed optic projections in the mouse. Proc R Soc Lond [Biol] 224:57-77.

Finlay BL, Pallas SL (1989) Control of cell number in the developing mammalian visual system. Prog Neurobiol 32:207-234.

Frade JM, Martí E, Bovolenta P, Rodríguez-Peña MA, Pérez-García D, Rohrer H, Edgar D, Rodríguez-Tébar A (1996) Insulin-like growth factor-I stimulates neurogenesis in chick retina by regulating expression of the $\alpha 6$ integrin subunit. Development 122:2497-2506.

Guillemot F, Joyner AL (1993) Dynamic expression of the murine Achaete-Scute homologue Mash-1 in the developing nervous system. Mech Dev 42:171-185.

Hernández-Sánchez C, López-Carranza A, Alarcón C, Rosa EJ, Pablo F (1995) Autocrine/paracrine role of insulin-related growth factors in neurogenesis: local expression and effects on cell proliferation and differentiation in retina. Proc Natl Acad Sci USA 92:9834-9838.

Hoskins SG (1985) Control of the development of the ipsilateral retinothalamic projection in Xenopus laevis by thyroxine: results and speculation. J Neurobiol 17:203-229.

Ilia M, Jeffery G (1996) Delayed neurogenesis in the albino retina: evidence of a role for melanin in regulating the pace of cell generation. Dev Brain Res 95:176-183.

Ilia M, Jeffery G (1998) Retinal mitosis is regulated by dopa, a melanin precursor that may influence the time at which cells exit the cell cycle: analysis of patterns of cell production in pigmented and albino retinae. $\mathrm{J}$ Comp Neurol, in press.
Jacobson M (1991) Developmental neurobiology. New York: Plenum.

Lia B, Williams RW, Chalupa LM (1986) Does axonal branching contribute to the overproduction of optic nerve fibers during early development of the cat's visual system? Brain Res 390:296-301.

Lillien L, Cepko C (1992) Control of proliferation in the retina: temporal changes in responsiveness to FGF and TGF $\alpha$. Development 115:253-266.

Linden R, Pinto LH (1985) Developmental genetics of the retina: evidence that the pearl mutation in the mouse affects the time course of natural cell death in the ganglion cell layer. Exp Brain Res 60:79-86.

Ma Y-T, Hsieh T, Forbes ME, Johnson JE, Frost DO (1998) BDNF injected into the superior colliculus reduces developmental retinal ganglion cell death. J Neurosci 18:2097-2107.

Macaione S, Di-Giorgio R, Nicotina P, Lentile R (1984) Retina maturation following administration of thyroxine in developing rats: effects on polyamine metabolism and glutamate decarboxylase. J Neurochem 43:303-315.

Montgomery JC, Silverman KA, Buchberg AM (1997) Chromosome 11. Mamm Genome 7:190-208.

Navagantes LC, Silveira LC, Santos GL (1996) Effect of congenital hypothyroidism on cell density in the ganglion cell layer of the rat retina. Braz J Med Biol Res 29:665-668.

Perry VH, Henderson Z, Linden R (1983) Postnatal changes in retinal ganglion cell and optic axon populations in the pigmented rat. J Comp Neurol 219:356-368.

Rager G, Rager U (1978) Systems-matching by degeneration. Exp Brain Res 33:65-78.

Rakic P, Riley K (1983) Overproduction and elimination of retinal axons in the fetal rhesus monkey. Science 219:1441-1444.

Rice DS, Williams RW, Goldowitz D (1995) Genetic control of retinal projections in inbred strains of albino mice. J Comp Neurol 354:459-469.

Rosa EJ, Arribas A, Frade JM, Rodríguez-Tébar A (1993) Role of neurotrophins in the control of neural development: neurotrophin-3 promotes both neuron differentiation and survival of cultured chick retinal cells. Neuroscience 58:347-352.

Sjöberg M, Vennström B, Forrest D (1992) Thyroid hormone receptors in chick retinal development: differential expression of mRNAs for $\alpha$ and N-terminal variant $\beta$ receptors. Development 114:39-47.

Watanabe T, Raff MC (1990) Rod photoreceptor development in vitro: intrinsic properties of proliferating neuroepithelial cells change as development proceeds in the rat retina. Neuron 2:461-467.

Williams MA, Piñon LGP, Linden R, Pinto LH (1990) The pearl mutation accelerates the schedule of natural cell death in the early postnatal retina. Exp Brain Res 82:393-400.

Williams RW, Borodkin M, Rakic P (1991) Growth cone distribution patterns in the optic nerve of fetal monkeys: implications for mechanisms of axonal guidance. J Neurosci 11:1081-1094.

Williams RW, Goldowitz D (1992) Lineage versus environment in embryonic retina: a revisionist perspective. Trends Neurosci 15:368-373.

Williams RW, Bastiani MJ, Lia B, Chalupa LM (1986) Growth cones, dying axons and developmental fluctuations in the fiber population of the cat's optic nerve. J Comp Neurol 246:32-69.

Williams RW, Strom RC, Rice DS, Goldowitz D (1996) Genetic and environmental control of variation in retinal ganglion cell number in mice. J Neurosci 16:7193-7205.

Williams RW, Strom RC, Goldowitz D (1998a) Natural variation in neuron number in mice is linked to a major quantitative trait locus on Chr 11. J Neurosci 18:138-146.

Williams RW, Strom RS, Zhou G, Yan Z (1998b) Genetic dissection of retinal development. Semin Cell Dev Biol 9:249-255.

Zamenhof S, Marthens E (1976) Neonatal and adult brain parameters in mice selected for adult brain weight. Dev Psychobiol 9:587-593. 